\title{
Improving Functional Characteristics of Wool and Some Synthetic Fibres
}

\author{
O. G. Allam \\ National Research Centre, Textile Research Division, Dokki, Cairo, Egypt \\ E-mail:omaimaalaam@yahoo.com \\ Received August 22, 2011; revised September 28, 2011; accepted October 5, 2011
}

\begin{abstract}
The present article reviews recent developments in different treatments that confer functional characteristics on wool and some synthetic fibers such as acrylic, polyamide and polyester of these functionalities mention is made of shrinkage-resistance, felt proofing, ant pilling, antimicrobial, surface properties (hydrophilic, soil -resistance, water and oil-repellency), self-cleaning, anti odor and flame retardant. The article also illustrates nanotechnology applications to improve and / or to induce some of these properties. Improvement of these properties can give the fibres an important position between the textile fibres which make them more convenient in different uses.
\end{abstract}

Keywords: Functional, Wool, Synthetic Fibres

\section{Introduction}

The different types of textiles are (A): natural fibres such as cotton, wool and silk) and (B): man-made fibers, synthetic fibres (polyester-polyamide-acrylic), regenerated cellulosic fibres (viscose) and their blend fibres. All fibers types are negatively affected by the economic slump. World wool production has continued downward, falling in 2008, from about 3\% to 1.16 million tons. Approximately world wool production is 1.3 million tons per year. On the other hand, the global production trend in synthetic fibres has been recently increased, especially polyester fibres as shown under:

There are considerable amount of textile deficiencies. Therefore, different methods of treatment are needed to improve them.

Textiles are sometimes finished by chemical processes to change their characteristics. In the 19th century and early 20th century starching was commonly used to make clothing more resistant to stains and wrinkles.

Recently with advances in technologies such as permanent press process, finishing agents have been used to strengthen fabrics and make them wrinkle free.

More recently, developed permanent treatments based on metallic nanoparticles for making textiles more resistant to water, stains, wrinkles, and pathogens have led to additional advancements. Textiles received a range of treatments before they reach the end-user: from formal- dehyde finishes (to improve crease-resistance) to biocides finishes and from flame retardants to dyeing of many types of fabris, the possibilities are almost endless.

However, many of these finishes may also have detrimental effects on the end user. Consequently, presence of chemical treatment, quality control and testing methods are of utmost importance [1-4].

The rapid growth in textile industry and in their end-uses has generated many opportunities for the application of innovative chemical finishes. Hence, it is important to show the functional characteristics of wool and some synthetic fibres such as felting \& shrinkage, pilling, microbial, surface characteristics, etc.

Organically grown fibres can be treated with toxic chemicals for the 'proofing' mentioned above, and these chemicals can cause health and environment problems [5].

\section{Functional Properties}

With respect to wool, there are two main deficiencies shrinkage (felting) and pilling that should be eliminated to. This could be achieved by varied treatments and methods of application, namely, chemical, enzymatic, cyclodextrin, sericin, and plasma treatments as outlined below.

\subsection{Shrinkage-Resistance}

\subsubsection{Chemical Treatments}

Felting and shrinkage constitute wool disadvantage. 
The hydrophobic nature and scale structure of the wool fiber led to the fiber to move towards their root end under mechanical action in the wet state [6].

Many methods and chemical treatments have been developed for preventing shrinkage of wool fibres. The first is coating with resins such as polyamide epichlorohydrin or grafting polymers onto wool fibres. The second is morphological modification of the cuticular cells by chemical or physical treatment [7].

Wool fibers were rendered shrink-proofing without causing any damage to the hydrophobic nature of the scale surface through treating them with glycerol polyglycidyl ether (GPE) in concentrated salt solutions.

The role of GPE is not to chemically modify the fibre surface, but to crosslink the cuticular cells to prevent their edges from prominence in aqueous media. Excellent shrinkage resistance can be imparted to wool by applying GPE in saturated $\mathrm{NaCl}$ (sodium chloride) solution in the presence of a reductive agent such as Sodium metabisulfite $\left(\mathrm{Na}_{2} \mathrm{~S}_{2} \mathrm{O}_{5}\right)$, while the hydrophobic nature of the surface remains unchanged [7].

In addition, as treatment for shrinkage in wool fabric, sodium methoxide or sodium hydroxide at low concentration in a 2-propanol medium was used [8].

Moreover, dichlorodicyanuric acid (DCCA) oxidation confers a negative charge on the wool fibre surface, generally attributed to conversion of cysteine amino acids to cysteic acid and the formation of cystine sulfonic acid [9-12]. Additionally DCCA is one of the oldest chlorinating reagents for imparting shrinkage resistance to wool. The 5\% DCCA / hydrogen peroxide treatment improves shrinkage resistance by $54 \%$ and whiteness by $63 \%$ when compared to untreated fabrics [13].

\subsubsection{Enzymes}

Enzymes are biocatalysts or activators which can speed up chemical processes that otherwise run slowly. The most of enzymatic processes are combined with chemicals or plasma radiations. A proteolytic enzyme derived from the bacterium streptomycin fradiae has been applied on wool to improve its shrinkage resistance properties.

Shrink reduction is greater with less intense washing treatments. Although there is a certain amount of shrinkage reduction in severe washing methods, the effect is not sufficient for practical purposes [14].

Pretreatment of the wool with proteolytic enzyme papain improve shrinkage resistance to wool tops.

This process may be considered as a zero-absorbable organohalogens (AOX) shrink-proofing treatment [15].

It was established that alkaline hydrogen peroxide system that includes dicyandiamide, gluconic acid, and triton surfactant, used alone or followed by enzyme treatments, control shrinkage in wool fabrics to $30 \%$ and
$1.2 \%$, respectively [16].

Shrinkage of wool fabric can be controlled by oxidation and protease treatment, however, strength loss usually results. There is reasonable expectation that by applying transglutaminase (TG) to oxidized and enzymatically treated wool, strength can be increased [17].

\subsubsection{Cyclodextrins}

Cyclodextrins are cyclic oligosaccharides. These molecules are able to form inclusion complexes with a large number of organic molecules. The properties of cyclodextrins enable them to be used in a variety of different textile applications. Cyclodextrins may act as auxiliaries in washing and dyeing processes. They could be made new functional properties for textiles [18]. Cyclodextrins are interesting in the optimization of textile technologies as well. They have been used to remove surfactants from the goods or to enhance activity of enzymatic processes in finishing processes like degumming, desizing, or felt-free finishing of wool [19].

\subsubsection{Sericin}

Sericin is a biopolymer of molecular weight ranges between 10-300 k Da. About 50000 ton of sericin is produced annually during degumming of silk. Utilization of sericin is limited to some nontextile uses; e.g., antioxidant in the field of medicine, cosmetics and food antibacterial products for diapers and wound dressing [20, 21]. Recently, Sericin is found to be efficient in felt proofing wool fibers, especially in the presence of a crosslinker such as Dimethylol Dihydroxy Ethylene Urea; (DMDHEU), Dimethyl Dihydroxy Ethylene Urea (DMeDHEU), or Epichlorohydrin (ECH). The felting resistance of wool fibres treated with the system Hydrogen peroxide $\left(\mathrm{H}_{2} \mathrm{O}_{2}\right)$ / Sodium sulfite $\left(\mathrm{Na}_{2} \mathrm{SO}_{3}\right)$ /sericin/ECH is the same as the felting resistance obtained by using commercially available synthetic polymers. Being a relatively cheap natural biodegradable polymer produced from renewable resources, sericin is an acceptable base for felt proofing treatments of wool tops [22].

\subsubsection{Plasma}

Plasma, as a very active tool, can be used to modify the surface of substrate known as plasma activation or plasma modification to impart some desired properties [23].

Molina et al., have treated wool fabric with water vapor plasma, which was produced in a radio-frequency (RF) reactor with $100 \mathrm{~Pa}$ and $100 \mathrm{~W}$ at different treatment times. The wool shrink tendency was clearly reduced [24]. There are many different ways to induce the ionization of gases such as Glow-Discharge, Corona Discharge and Dielectric-Barrier Discharge. It is published that the oxygen plasma treatments by using a glow discharge 
generator, of four types of wool fibre having different diameters decreases felting [25]. It has recently been shown that anti-felting behavior of wool fibres was improved using Argon (Ar) plasma treatment as shown as the following Figure 1 [26].

a) Untreated

b) No. 1: Sample was placed on the cathode: Ar gas was used for $7 \mathrm{~min}$

c) No. 2: Sample was placed on the cathode: $\mathrm{O}_{2}$ gas was used for $7 \mathrm{~min}$

d) No. 3: Sample was placed on the Anode: $\mathrm{O}_{2}$ gas was used for $7 \mathrm{~min}$

e) No. 4: Sample was placed on the Anode: $\mathrm{N}_{2}$ gas was used for $7 \mathrm{~min}$

\subsection{Anti-Pilling}

Pilling of wool is a physical phenomenon that takes place on the surface of a garment. The pills are formed during wear and washing by the entanglement of loose fibres present on the surface [27].

\subsubsection{Plasma}

Plasma treatment of textile fabrics and yarns was investigated to improve pilling.

A thin film ( $\mathrm{Si}: \mathrm{O}_{\mathrm{x}}: \mathrm{C}_{\mathrm{y}}: \mathrm{H}_{\mathrm{z}}$ ) was deposited on knitted wool fabrics by plasma low pressure using hexamethyldisiloxane as the monomer, and argon and oxygen as feed gases to reducing pill formation of wool [28].

\subsubsection{Enzymes}

Wool fabric can modified with ecologically acceptable UV-assisted enzymatic treatments to reduce its pilling with an acceptable loss in weight and strength of the fabric [29]. Pilling is undesirable property that affects handle and appearance of fabrics and a serious problem for textile industry [27]. Using Hexanediol or pentaerythritol to crosslink acrylic fibres that contain the methyl acryl ate group improved the pilling performance of acrylic fibres [30,31].

\subsection{Antimicrobial}

Textiles have long been recognized as media to support the growth of microorganisms such as bacteria and fungi. These microorganisms are found almost everywhere in the environment and can multiply quickly when basic requirements, such as moisture, nutrients and temperature are met. Most synthetic fibres, due to their high hydrophobic, are more resistant to attacks by microorganisms than natural fibres [32].

The application methods of antimicrobial agents and some of the most recent developments in antimicrobial treatments of textiles use various active agents such as silver, quaternary ammonium salts, polyhexamethylene biguanide, triclosan, chitosan, dyes and regenerable $\mathrm{N}$ halamine compounds and peroxyacids [33].

Methods of anti-microbial treatment of fibers include:

(1) Grafted, copolymers, (2) Synthetic dyes, (3) Qua-



(a) Untreated

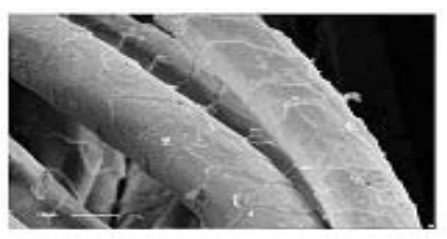

(b) No 1

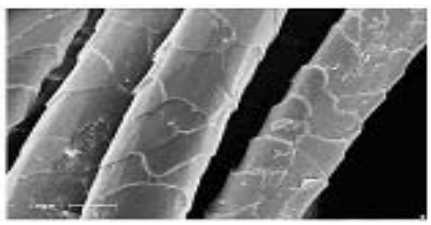

(d) No 3

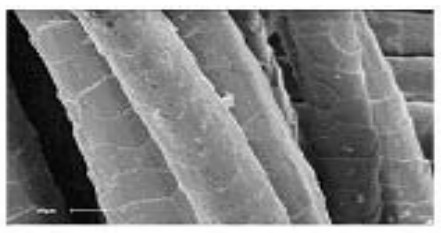

(c) No 2

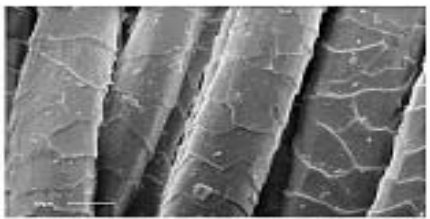

(e) No 4

Figure 1. Sample description. 
ternary ammonium compounds, (4) Chitosan, (5) cyclodextrins, (6) plasma.

\subsubsection{Grafted Copolymers}

In order to obtain textile materials with antimicrobial performances, the following procedures are used: (1) impregnation of the fibrous material with a solution, suspension or emulsion of the bactericidal (fungicidal) product; (2) padding of an antimicrobial product, from its soluble state into an insoluble one on the fibrous material; (3) binding of an antimicrobial product on the fibre through chemical bonds (ionic, coordinative, covalent); (4) immersion of a bactericidal product either in the spinning solution or melt, during preparation of the chemical fibers. To have antimicrobial wool textile materials, methods based on binding of a bactericidal product to functional groups of the fibrous material through chemical links are used. Chemical binding of biologically active products on wool fibres is performed either by synthesis of grafted copolymers (bactericidal products bind to the wool keratin) or by applying antimicrobial dyes (acridines, aminoacridines, quinones, methylene blue, etc.). The fabrics obtained by wool grafting demonstrated good ionic exchange properties [34,35].

\subsubsection{Synthetic Dyes}

Some synthetic dyes are used in textile industry, e.g. metallic dyestuff and have been specifically made with antimicrobial activity.

New series of azo disperse dyestuffs; prepared by the reaction of sulphanilamidodiazonium chloride derivatives with indan-1, 3-dione, gave excellent dyeing and antimicrobial results on wool and nylon [36].

Novel cationic dyes were synthesized, showed varying levels of antimicrobial activities, depending on their structures, but when applied to acrylic fabrics the antimicrobial durability generally did not last for more than five washes [37].

\subsubsection{Quaternary Ammonium Compounds}

Quaternary ammonium compounds (QACs) have been widely used as disinfectants [38]. The attachment of QAC to a textile substrate is believed to be predominantly by ionic interaction between the cationic QAC and anionic fibre surface. Therefore, fibres such as acrilan and orlon which contain carboxylic or sulfonate groups QAC can be directly exhausted under near boiling conditions.

Similarly, the glutamyl and aspartyl residues in wool provide carboxylic groups. Exhaustion of (QACs) onto wool can render it antimicrobial with durability to 10 launderings [39-41]. In general durable antimicrobial properties could be achieved on acrylic fabrics by chemical incorporation with quaternary ammonium salts such as cetylpyridinium. The study found that cetylpyridinium concentration affected the adsorption process and antimicrobial properties of acrylic fabrics. The cetylpyridinium chloride could form ionic interactions with anionic groups on acrylic fibres, which contribute to durable antimicrobial functions [42].

Other synthetic fibres such as nylon 66 contain fewer reactive sites and are quite resistant to chemical modification procedures, including antimicrobial finishing. Sun and his colleagues have dyed out the fabrics first with acid dyes before application of QACs under alkaline conditions. The ionic interaction between the dye molecules and the QAC was strong to provide a semi durable antimicrobial finishing [43,44].

\subsubsection{Chitosan}

Chitosan was found to inhibit the growth of microbes $[45,46]$. It is a naturally available biopolymer which is now increasingly being used as a functional finish on textile substrates to impart antimicrobial characteristics.

Henna a natural dye with proven bactericidal properties was applied on wool fabrics along with chitosan to impart antimicrobial characteristics [47]. Acrylic antimicrobial fibres were prepared by coating chitosan on chemically modified acrylic fibres [48]. The chitosan-modified acrylic fibres showed excellent antimicrobial activity against Staphylococcus aureus, compared with the untreated original acrylic fibres. The modified acrylic fibres treated with chitosan showed high durability to laundering probably due to strong ionic interaction between chitosan and the modified. The direct antimicrobial finishing of acrylic fibres may have applicability both in sport wear and biomedical textiles field, by providing some additional functions of odor control [49]. Moreover waterborne polyurethane is prepared and reacted with chitosan as chain extender. The Prepared polyurethane chitosan was studied as antimicrobial agent of acrylic fabrics [50].

\subsubsection{Cyclodextrins}

Cyclodextrins (CDs) play a significant role in the antimicrobial agents for Polyamide fabrics [51,52]. It was found that the treatment with 30-50 g/l Cyclodextrin (CD) or monochlorotriazinyl cyclodextrin (CD-T) has enhanced the antimicrobial activity; the highest antimicrobial activity was imparted upon treatment with CDT than CD [53]. The addition of quaternary ammonium salts increases the antimicrobial activity [54].

\subsubsection{Plasma}

As some life styles have become more active, sportswear, 
active wear, and casual wear may become more easily contaminated by perspiration leading to bacterial growth and body odors [55]; especially synthetic fabrics. Plasma treatment can take the place of the traditional chemical processes. However, Plasma technologies still find difficulties in being widely accepted by the textile industry [56]. Plasma grafting is grafting of molecules on the material surface after Plasma activation [57].

The properties of polyester fabrics grafted with chitosan oligomers/polymers after being activated by atmospheric pressure plasmas were evaluated. The antibacterial effect was most evident when the surface of fabrics was activated by atmospheric pressure plasma for 60 to 120 seconds and grafted with chitosan oligomers. [58].

\subsection{Hydrophilicty, Soil-Resistance, Water-Repellency Oil-repellency}

There properties could be imparted to wool and other fibres through:

(1) Chemical, (2) Enzymes, (3) Cyclodextrins, (4) Casein, (5) Plasma treatments as cited below.

\subsubsection{Chemical Treatments}

It is well known that surface characteristic of fibres play an important role in the functional and aesthetic properties of their fabrics, and many surface modifications by chemical treatments are able to improve textile properties. Exposure of reactive chemical functional groups through controlled surface lipid removal provides a means for covalent attachment of novel molecular entities to the wool fibre surface.

The surface modification of wool by means of aqueous hydroxylamine treatment was investigated [59].

\subsubsection{Enzymes}

Uses of enzymes available for application in textile wet processing

Continues to increase each year. Clearly the use of various enzymes to carry out surface hydrolysis of polyester fibres to increase fibre hydrophilicity has been reported. The use of nitrile hydrates enzyme to modify the surface of acrylic fibres converting the surface nitrile groups into amide groups, thereby increasing the hydrophilicity and the antistatic properties of the fibres [6064].

\subsubsection{Cyclodextrins}

On treating textile materials with cyclodextrin-containing finishes, the physically fixed cyclodextrins allow the easy removal of sweat or sweat degradation products from the textile by preventing their penetration into the fibre interior [65].
Wool and synthetic fabrics (polyester) were treated with deodorizing agents formulated with cyclodextrin to attain wash resistant and odor-absorbing properties.A number of examples are given for permanent fixation of various cyclodextrin derivatives via functional groups onto fibre surfaces, including hydrophobically substituted derivatives on synthetic fibres and cationically and anionically modified derivatives on polyamide fabric. The cyclodextrin derivatives contained functional groups such as dihydroxypropyl, hydroxyhexyl, alkoxyhydroxypropyl, phenoxyhydroxypropyl, carboxymethyl, hydroxytrimethylammonium chloride, and chlorotriazinyl [66].

\subsubsection{Casein}

Acrylic fibre, due to its relatively cheap price and many superior characteristics such as soft, wool-like hand, machine washable, dayable and excellent colour retention, is used in the textile industry. But acrylic fibre also exhibits some obvious disadvantages, which greatly limits its further applications [68]. A novel chemical modification method of acrylic fibre was employed by grafting of casein-a natural polymer-onto the surface of acrylic fibre. The results showed that casein had been grafted onto the acrylic fibre to improve the surface of acrylic fibre. Moisture absorption, water retention and specific electric resistance were found to be improved as compared with the untreated fibre [67].

\subsubsection{Plasma}

Plasma pretreatments are environmentally benign and energy efficient processes for modifying the surface chemistry of materials [68-69]. And also they can be applied to all kinds of fibres, yarns or fabrics (such as wool, polyacrylic, polyamide, and polyester,) to give these materials an extremely wide range of functionalities (anti-felting, antistatic, flame retardancy and oleophobicity) [70]. Wool is partially-ionized in gas normally generated by an electrical discharge at near ambient temperatures.

Plasma, often considered as the fourth state of matter, is composed of an ionized gas containing a mixture of ions, electron, neutral and excited molecule, and photons. The main attraction of plasma in industrial processing is in the avoidance of chemical effluents, beside rapid reaction times and high cleaning efficiency. Many surface properties of synthetic fibers can be successfully altered using plasma technology. These surface properties include wet ability, dye ability and electrical conductivity [71].

In addition, the harsher handle imparted by plasma modification is improved with silicone treatment. The results show that the plasma pretreatment modifies the 
cuticle surface of the wool fibres and increases the reactivity of the wool fabric toward silicone polymers [72].

Glow-discharge plasma treatments can be used for activation, grafting, deposition or etching wool fabric samples which have been treated with a trichloroethylene solution of zonyl fluoro monomer in argon plasma to obtain high levels of water-and oil-repellency [73].

Moreover fabrics were treated in low temperature plasma to increase soil resistance.

Polyacrylonitrile fabrics were directly treated in acrylic acid, water, and argon plasma. Dye ability and soil resistance of polyacrylonitrile fabrics were significantly improved by these methods and more hydrophilic surfaces were created [74].

It was reported that nylon fabrics were treated with different plasma gases exhibit a slight decrease in the air permeability probably due to plasma action whereby increasing the fabric thickness and a change in the fabric surface morphology accrued. The change in the thermal properties of the treated polyamide fabrics can be attributed to the amount of air trapped between the yarns [75].

Polyamide fabrics have characteristics in terms of water-repellency, smoother surface and wet ability when they were treated with tetra fluoronerthane low temperature plasma [72] and treated with a low-temperature oxygen plasma respectively [73]. Polyester fabrics have also been treated with tetra fluoronerthane low temperature plasma to modify the water-repellency [76]. The wet ability of polyester fabric was improved using a vacuum ultraviolet excimer lamp [77].

Polyester fibres are usually dyed at a high pressure and high temperature. Plasma treatments modify the fibres surfaces to improve dyeing characteristics. Treatment led to increase acid dye ability and decrease dye ability with disperse dyes. Polyester fibres treated in a glow discharge with acrylic acid can be dyed to deep colours with basic dyes.

Furthermore the surface modification of polyester fabric with metal salt before plasma treatment plays a vital role in improving light fastness [78]. UV-laser pretreatment can be used to induce surface modification of polyester and polyamide fabrics for high performance [79].

\subsection{Flame Retardancy}

All textile fibers consist of long chains of polymeric materials and the burning behavior of the fibers is determined largely by the chemical properties of these materials [80]. Natural fibres are used in interior parts of buses or cars or as seat fabrics, for their comfort and dye ability properties but they are easily flammable.

Wool is the most resistant to burning. It is difficult to ignite; any flame spread slowly and is easily extinguished. The residue is a low-temperature, frigate, non-sticking ash (unlink the acrylic, polyamide, and polyester fibers) [81].

Acrylic fibers are used mainly in the decorating and home textile sectors in addition to the clothing sector, especiallly for knitted goods. These fields of application are becoming increasingly important in terms of flameproofing regulations.

The developments in flame retardation of acrylic fibers were produced by various methods, for example, incorporation of co monomers like vinyl chloride or vinylidene chloride through copolymerization, using certain modifiers in the spinning dope or in the spinning bath, and surface modification, including finishing.

Treatment of acrylic fibers with hydroxyl amine hydrochloride, hydrazine hydrate, or dibutyl tin ethyl maleate produces flame-retardant acrylics fabrics [82,83].

Bicomponent fibres have found considerable application in woven carpets because their increased bulk and cover offer advantages over traditionally used fibres. Improved flame-resistant fibres incorporating halogen compounds have been developed to meet flammability requirements for carpets [84].

\subsection{Self-Cleaning, Anti-Odor, Oil-Repellency, Water-Repellency and Antimicrobial Nano Technology Application}

\subsubsection{Nanoparticles}

Recent developments of nanotechnology directed to applications in textile areas including fibres are considered. The first commercial application of nano finishes is found in textiles in the form of nanoparticles through finishing processes. Nanotechnology can provide high durability for fabrics, because nanoparticles have a large surface area-to-volume ratio and high surface energy, thus presenting better affinity for fabrics and leading to an increase in durability of the function.

The present status of nanotechnology used in textiles to improve different functional properties of textiles, such as high-tech fibres, self-cleaning, anti-odor, oil-repellency, water-repellency, soil resistance, wrinkle resistance, anti-static and UV-protection, flame retardant, improvement of dye ability, antimicrobial and so on. Some of these applications of nanoparticles to textiles are considered [85].

As the particle size decreases the number of molecules in the surface relative to the bulk increases, giving new and unexpected properties. This has been illustrated schematically in the following Figure 2 [94].

Major research and development successes in technical applications for wool in the past five years have opened up new and exciting opportunities for this old, 


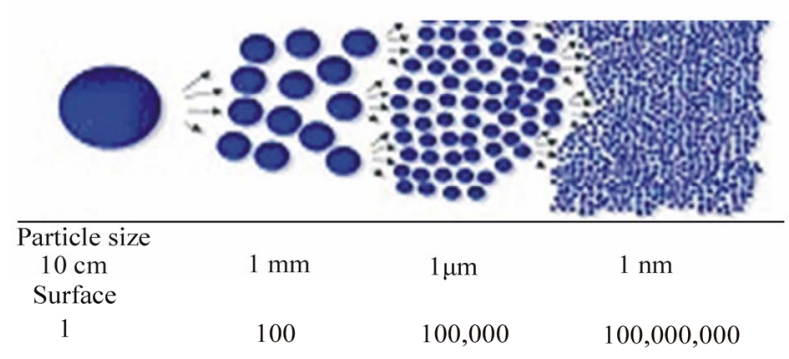

Figure 2. Schematic Representation of particle size and surface at nano-scale.

familiar fibre. Nanotechnology is the science of self-regulating materials and processes that are controlled at the molecular level.

It has improved the physical nature of the wool fibre surface to introduce particular functionalities such as static control, water-repellency, etc.

Several methods can apply coating onto fabrics, including spraying, transfer printing, washing, rinsing and padding. Padding is the most commonly used The nano-particles are attached to the fabrics with the use of a padder adjusted to suitable pressure and speed, followed by drying and curing [86,87].

\subsubsection{Polymer Anocomposites}

In this review, we have compiled the current research in polymer nano composite-based nano finishes for multifunctional textiles as shown in the next Figure 3 [94].

A simple method of obtaining a super hydrophobic surface for wool textile finishing has been reported. This method involves devising a comb like polymer comprising acryl ate and organic siloxane.

This combination can exhibit some unique characteristics like an increase of the cohesiveness and film form-favoring properties. Also, the long Si-O-Si chain with low surface energy can be utilized to enhance the water-repellency [88].

\subsubsection{Ag-Loading Nano $\mathrm{SiO}_{2}$}

In wool fibre, the free carboxyl groups of aspartyl and glutamyl residues are considered the most likely binding sites for metal ions .In this treatment, silver nanoparticles are applied to wool using typical fabric and garment dye systems. The original properties of the wool, including handle and dye ability, remain unchanged after the treatment $[89,90]$.

Recently the wool fibre with Ag-Loading $\mathrm{SiO}_{2}$ nanoantibacterial agent was prepared by the method of photo grafting. Under ultraviolet irradiation the structure of wool fiber was changed, a lot of active groups were formed and grafting with Ag-Loading $\mathrm{SiO}_{2}$ was realized. And antibacterial layer was formed on the surface of wool fibre [91].

Nano-Tex has developed two superior water and oil-repellent products based on custom designed fluorocarbon-containing polymers applied to all major apparel fabrics, including wool, polyester and naylon [92].

Chitosan, polymer is antibacterial, non-toxic, biodegradable and biocompatible. Research work has been done on the preparation of chitosan/silver nanocomposites in solid forms, such as fibres, powders and films. An emulsion of chitosan-silver oxide nanoparticles can be easily applied onto textile fabrics using conventional pad-drycure process. The finish was found to be durable and wash fast as it remained effective after 20 washings [93].

In order to achieve desired level of antibacterial efficiency of polyamide fabrics, the loading of the $\mathrm{Ag}$ nanoparticles (NPs) after dyeing is recommended.

In recent years methods and techniques of producing antimicrobial acrylic fibres was studied using nano-antimicrobial materials. The modified fibres are useful for clothing, beddings and interior materials.

Anti-bacterial nanosized silver turned out to be an excellent antibacterial agent and to control the development of odor from perspiration for polyester fibres, which are the most widely used in textile industry such as surgical mask, diaper filter, hygienic band and sportswear [9498].

\subsubsection{Titanium Dioxide Nanoparticles}

The application of nano-particles to textile materials has been the object of several studies aimed at producing finished fabrics with different performances. For example nano-sized silver (nano-Ag), Zinc oxide ( $\mathrm{ZnO}$ ) and titanium dioxide $\left(\mathrm{TiO}_{2}\right)$ nano particles has been used for imparting antibacterial properties and UV-blocking properties. $\mathrm{ZnO}$ and titanium dioxide $\left(\mathrm{TiO}_{2}\right)$ are nontoxic and chemically stable under exposure to both high temperatures and UV.

$\mathrm{TiO}_{2}$ is one of the most popular and promising materials in photo catalytic application due to its strong oxidizing power. $\mathrm{TiO}_{2}$ is commercially available and easy to prepare in the laboratory. Nano-sized silver, titanium dioxide and zinc oxide are used for imparting self-cleaning and antibacterial properties [99].

\subsubsection{Smart Silver}

Nano-Tex has developed two superior water and oil-repellent products based on custom designed fluorocarbon-containing polymers as a water and oil repellent treatment that can be applied to all major apparel fabrics, including wool, polyester, nylon, rayon and blends.

It has announced the availability of smart silver permanent anti-odor/antimicrobial for $100 \%$ wool. This new 


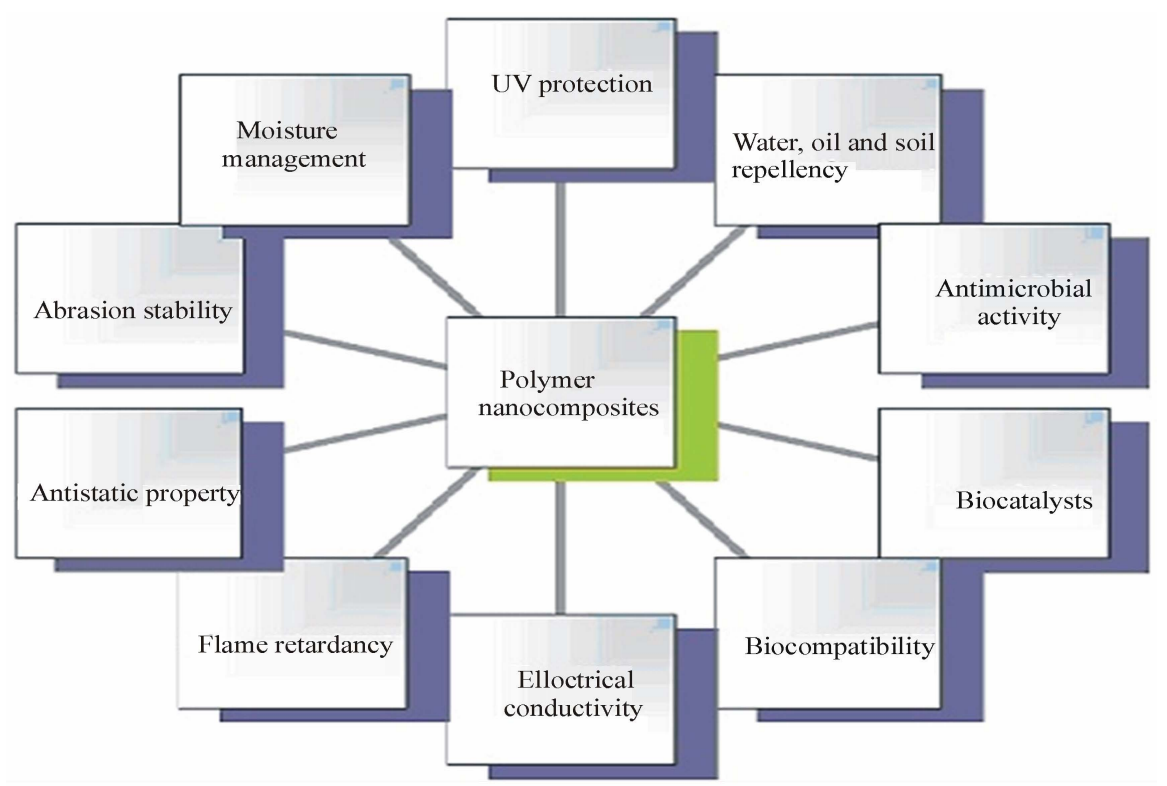

Figure 3. Some possibilities of textile functionalization using polymer nanocomposites.

product joins the current line of smart silver for polyester, nylon, polypropylene, cotton and rayon. Smart Silver the smarter anti-odor and antimicrobial anti-odor performance to fabrics without any compromises in fabric quality.

Smart silver is applied to wool using typical fabric and garment dye systems. Smart silver imparts anti-odor/ antimicrobial capabilities to wool through modifications engineered at the molecular level.

Smart silver is permanent, safe, and fully compatible with existing manufacturing processes for fibre and fabrics. Smart silver-enhanced fibers can be used to create odor-resistant undergarments, hats, gloves, socks, T-shirts, sweaters, carpets and more [100-102].

\subsubsection{Nanoemulsions}

Sandoperm SE1 oil liq., produces nanoemulsions which impart an inner softness. Applicable to polyamide and polyester the hydroplilicity impart is classed as permanent to washing. When applied on synthetic fabrics a so-called "silky-touch" can be obtained [64].

\section{Conclusions}

It has been possible within this review to discuss some of the functional characteristics of wool and synthetic fibres (acrylic, polyamide and polyester) brought about by different methods. The latter are exemplified under.

Wool was treated with glycerol polyglycidylether (GPE) in concentrated salt solutions. In addition, the use of sodium methoxide or sodium hydroxide in a 2-propanol medium to over come shrinkage of wool. DCCA (Di- chlorodicyanuric acid) treatments improve shrinkage and pilling. Finally chemical treatment followed by enzyme is better especially in industry.

Enzymes are biocatalysts. It can be used, to overcome disadvantages properties such as shrinkage, pilling, hydrophilic, etc. for wool and synthetic fibers. Sericin is a biopolymer which can be used for effecting ant felting properties of wool. Moreover casein, a natural polymer was carried and to improve the surface of acrylic fabrics. The application of cyclodextrins (CDs) on wool, acrylic, polyamide and polyester led to reduce shrinkage, felting and pilling. Meanwhile this application led to antimicrobial, hydrophilic, soil-resistant, etc. Their use will increase because they are non-toxic and biodegrable, thereby offering "green" solutions to enhance these important functionalities for textile.

Plasma technology, as a very active tool applied to wool to modify the surface substrate. In the long term the increasing importance of environmental issues will favour the use of this technology

Nanotechnology in the textile is mainly being tried into areas of fibre formation and processing of fabric. In processing area it helps in improving properties like wrinkle-resistance, soil and water repellency, antistatic, antibacterial and UV protection. Nano finishes lead to antibacterial and UV blocking properties given by silver (Ag), titanium dioxide $\left(\mathrm{liO}_{2}\right)$ and zinc oxide $(\mathrm{ZnO})$ nano particles are usually used.

\section{Future Outlook}

Improvement of functional characteristics of textile has 
been remained important to the textile industry. Economic forces, market demands, and environmental concerns will shape the direction that chemical development for functional characteristics will take. Global competitions are requiring textile chemicals at lower cost, by reducing the amount of water to be shipped. Often, the use of a textile chemical involves generating undesirable side effects. Products that require less energy and water perform these functional properties will be preferred such as plasma. Textile industries see a promising future for plasma technology, with the environmental and energy conservation benefits, in developing high-performance materials for the world market. Cyclodextrins are non-toxic and biodegradable, there by offering "green" solutions to enhance the properties and providing new functionalities to textile products. Biopolymer such as sericin, etc. is preferred to be used in order to improve functional properties due to their cheaper price than other chemicals and environmentally safe. In the future nanotechnology will overcome the limitations of applying conventional methods to impart certain properties to textile materials. The improvements on the application areas of nanotechnology in textile industry such as anti-bacterial textiles, antistatic textile, flame-retardant textiles, etc. will be increasing.

\section{References}

[1] “An Introduction to Textile Terms,” August 6, 2006. http://www.textilemuseum.org/PDFs/TextileTerms.pdf

[2] K. E. Perepelkin, "Principles and Methods of Modification of Fibers and Fiber Material," Fibre, Chemistry, Vol. 37, 2005, pp. 123-140. doi:10.1007/s10692-005-0069-6

[3] S. D. Worley and G. Sun, "Biocidal Polymers," Trends polymer Science, Vol. 4, 1996, pp. 364-370.

[4] H. Mucha, D. Höffer, S. Abfalg and M. Swerev, "Antimicrobial Finishes and Modifications," Melliand International, Vol. 4, 2002, pp. 53-56.

[5] J. Ellis, "Development in the Shrink-Resist Processing of Wool,” Aachen Textiltagung, No. 122, 1996, pp. 113.

[6] R. Makinson, "Shrink Proofing of Wool," New York, Marcel Dekker, 1979, pp. 264-338.

[7] U. Ryo, S. Yutaka, I. hiraku, S. Munenori and M. Takeki, "Shrink Resist Treatment for Wool Using Multifunctional Epoxides,” Textile Research Journal, Vol. 61, No. 2, 1991, pp. 89-93. doi:10.1177/004051759106100206

[8] R. Julià, J. Solà and P. Erra, "Influence of Water in Wool Treatments with Sodium Methoxide in 2-Propanol Medium to Improve Shrink Resistance," Textile Research Journal, Vol. 60, No. 3, 1990, pp. 123-128. doi:10.1177/004051759006000301

[9] R. L. Breier, “A New Enzymatic Ant felt and Ant pilling Finishing for Wool,” Proceedings of 10th International
Wool Textile Conference, Aachen, November 2000, p. 4.

[10] L. Coderch, M. R. Julia and P. Frra, "Modification of Wool Fibers Subjected to Shrink proofing Derivative processes," Proceedings of 8th International Wool Textile Research Conference, Vol. 4, Wool Organization of New Zealand, 1990, pp. 370-379.

[11] L. Coderch, A. Pinazo and P. Erra, "Derivative Wool Shrinkage Processing,” Textile Research Journal, Vol. 62, 1992, pp. 302-306.

[12] J. C. Cosnard, "Structure Modification by Ant felt Treatments with Salts of Dichloroisocyanuric Acid," Applied Polymer Symposium, Vol. 18, 1971, pp. 701-706.

[13] M. C. Jeanette, J. Yao and N. Alberto, "DCCA Shrink Proofing of Wool Part 1: Importance of Antichlor Nation,” Textile Research Journal, Vol. 74, 2004, pp. 555-560. doi:10.1177/004051750407400616

[14] A. Riva, J. Cegarra and R. Prieto, "The Role of an Enzyme in Reducing Wool Shrinkage,” Journal of Society dyers and colors, Vol. 109, 1993, pp. 210-213.

[15] H. El-Sayed, A. Kantouch, E. Heine and H. Höker, "Developing a Zero-AOX Shrink-Resist Process for Wool Part 1: Preliminary Results,” Color Technology, Vol. 117, 2001, pp. 234-238. doi:10.1111/j.1478-4408.2001.tb00068.x

[16] M. C. Jeanette, J. Yao and G. P. John, “Combined Bleaching, Shrinkage Prevention and Biopolishing of Wool Fabrics,” Textile Research Journal, Vol. 75, No. 2, 2005, pp. 169-1764. doi:10.1177/004051750507500215

[17] M. C. Jeanette, "Enzyme-Mediated Cross Linking of Wool, Part 1: Transglutaminase,” Textile Research Journal, Vol. 77, No. 4, 2007, pp. 214-221. doi:10.1177/0040517507076327

[18] H. J. Buchman, U. Denter, D. Knitter and E. Schollmeyer, "The Use of Cyclodextrines in Textile Processes-An Overview,” Journal of Textile Institute, Vol. 89, 1998, pp. 554-561.

[19] K. Opwis, E. Bach, H. J. Buchman, D. Knitter and E. Schollmeyer, "Stabilisierung Enzymatischer Tilveredlungsprozesse Durch Cyclodextrine,” Melliand Textilber, Vol. 79, 1998, pp. 545-546.

[20] S. Sarovat, B. Sudatis, P. Meeslipa, B. P. Grady and R. Magaraphen, "The Use of Sericin As an Antioxidant and Antimicrobial for Polluted Air Treatment," Review of Advanced Materials Science, Vol. 5, 2003, pp. 193-198.

[21] Y. O. Zhang, "Applications of Natural Silk Protein Sericin in Biomaterials,” Biotechnology Advances, Vol. 20, 2002, pp. 91-96. doi:10.1016/S0734-9750(02)00003-4

[22] O. G. Allam, H. El-Sayed, A. Kant ouch and K. Haggag, "Use of Sericin in Felt Proofing of Wool," Journal of Natural Fibers, Vol. 6, 2009, pp. 14-26. doi:10.1080/15440470802699802

[23] S. Pane, "Acrylic Fabric Treated With Plasma for Outdoor Application,” Journal of Industrial Textile, Vol. 31, 2001, pp. 135-145. doi:10.1106/YVCC-FTJN-9K28-3974 
[24] R. Molina, "Surface Characterization of Keratin Fibres Treated by Water Vapour Plasma," Surface and interface analysis, Vol. 35, 2003, pp. 128-135. doi:10.1002/sia.1510

[25] C. W. Kan, "Development of Low Temperature Plasma, Technology on Wool," The 6th Asian Textile Conference, Innovation and Globalization, Proceedings, August, Hong Kong, 2001, pp. 22-24.

[26] M. Masukuni and I. Norihiro, "Relationship Between Anti-Felting Properties and Physicochemical Properties of Wool Fibers Treated with Ar-Plasma," Textile Research Journal, Vol. 89, 2006, pp. 687-694.

[27] J. O. Ukponmwan, Mukhopadhyay and K. N. Chatterjee, "Pilling," Textile Progress, Vol. 28, 1990, pp. 1-55. doi:10.1080/00405169808688874

[28] M. Raffaella, L. Guiseppina, Riccardo, M. Giorgio, R. Fabio, M. Alessio and V. Espedito, "Characterization of Plasma-Coated Wool Fabrics,” Textile Research Journal, Vol. 9, 2009, pp. 853-861.

[29] H. El-Sayed and E. El-Khatib, "Modification of Wool Fabric Using Ecologically Acceptable UV-Assisted Treatments," Journal of Chemical Technology and Biotechnology, Vol. 80, No. 10, 2005, pp. 1111-1117. doi:10.1002/jctb. 1290

[30] P. J. Brown, M. Sultan and J. H. Nobbs, "Cross Linking Acrylic Fibres with Hexanediol and Pentaerythritol," American Association of Textile Chemists and Colorists, Vol. 3, No. 2, 2002, pp. 46-50.

[31] M. Isamu and O. Shojiro, "Chemical Modification of Jersey Prepared with Synthetic Fibres Modification of Acrylic Fibre-Wool Blend,” Kanagawa-ken Kogyo Shikensho, Vol. 30, 1971, pp. 1-7.

[32] R. Purwar and M. Joshi, "Recent Developments in Antimicrobial Finishing of Textiles: A Review," American Association of Textile Chemists and Colorists, Vol. 4, 2004, pp. 22-26.

[33] G. Yuan and C. Robin, "Recent Advances in Antimicrobial Treatments of textiles," Textile Research Journal, Vol. 78, No. 1, 2008, pp. 60-72. doi:10.1177/0040517507082332

[34] C. Diana, O. Simona and V. Narcisa, "Biofunctionalization of Textile Materials by Antimicrobial Treatments: A Critical Overview,” Romanian Biotechnological Letters, Vol. 15, No. 1, 2010.

[35] M. R. Infante, M. Diz, A. Pinazo and P. Erra, "Microbial Resistance of Wool Fabric Treated with Cbis-Quats Compounds,” Journal of Applied Bacteriology, Vol. 81, 1996, pp. 212-216. doi:10.1111/j.1365-2672.1996.tb04503.x

[36] A. Z. Sayed and M. S. A. El-Gaby, "Synthesis of Novel Dye Stuffs Containing Sulphonamido Moieties and Their Application on Wool and Polyamide Fibres," Color Technology, Vol. 117, 2001, pp. 293-297. doi:10.1111/j.1478-4408.2001.tb00078.x

[37] M. H. Ma and G. Sun, “Antimicrobial Cationic Dyes,
Part 3: Simultaneous Dyeing and Antimicrobial Finishing of Acrylic Fabrics,” Dyes and Pigments, Vol. 66, 2005, pp. 33-41. doi:10.1016/j.dyepig.2004.09.001

[38] S. R. Karmakar, "Chemical Technology in the Pre-Treatment Processes of Textiles,” Elsevier: Amsterdam, 1999, pp. 15-17.

[39] T. Zhao and G. Sun, "Antimicrobial Finishing of Wool Fabrics with Quaternary Amino Pyridinium Salts,” Journal Applied Polymer Science, Vol. 103, 2006, pp. 482-486. doi:10.1002/app.24986

[40] Z. Ping and S. Gang, "Antimicrobial Finishing of Wool Fabrics Using Quaternary Ammonium Salts,” Journal of Applied Polymer Science, Vol. 93, No. 3, 2004, pp. 1037-1041.

[41] Z. S. Cai and G. Sun, "Antimicrobial Finishing of Acrilan Fabrics with Cetylpyridinium Chloride,” Journal of Applied Polymer Science, Vol. 94, 2004, pp. 243-247. doi:10.1002/app.20876

[42] C. Zaisheng and S. Gang, “Antimicrobial Finishing of Acrilan Fabrics with Cetylpyridinium Chloride: Affected Properties and Structures," Journal of Applied Polymer Science, Vol. 97, pp. 1227-1236.

[43] Y. H. Kim and G. Sun, "Dye Molecules as Bridges for Functional Modifications of Naylon: Antimicrobial Functions," Textile Research Journal, Vol. 72, 2002, pp. 1052-1056.

[44] Y. H. Kim and G. Sun, "Durable Antimicrobial Nylon Fabrics with Acid Dyes and a Quaternary Ammonium Salts," Textile Research Journal, Vol. 71, 2001, pp. 318-323. doi:10.1177/004051750107100407

[45] M. Rinaudo, "Chitin and Chitosan: Properties and Applications,” Progress in Polymer Science, Vol. 31, 2006, pp. 603-632. doi:10.1016/j.progpolymsci.2006.06.001

[46] S. H. Lim and S. M. Hudson, "Review of Chatoyant and its Derivatives as Antimicrobial Agents and their Uses as Textile Chemicals," Journal of Macromol Science Polymer Review, Vol. 43, 2003, pp. 227-269.

[47] V. R. Giridev, J. Venugopal, S. Sudha, G. Deepika and S. Ramakrishna, "Dyeing and Antimicrobial Characteristics of Chitosan Treated Wool Fabrics with Henna Dye,” Carbohydrate Polymers, Vol. 75, 2009, pp. 646-650. doi:10.1016/j.carbpol.2008.09.003

[48] K. So-Hyun, L. Taek Seung and P. Wonho, "Preparation of Antimicrobial Fibres Through Chemical Modification of Acrylic Fibres," Journal of the Korean Fiber Society, Vol. 39, No. 4, 2002, pp. 390-395.

[49] G. SUN, “Bioactive Fibers and Polymers,” J. V. Edwards, T. L., Editors, American Chemical Society, Symposium Series No.792, 2001, p. 37.

[50] A. Atef El-Sayed, L. K. El Gabry and O. G. Allam, “Application of Prepared Waterborne Polyurethane Extended with Chitosan to Impart Antibacterial Properties to Ac- 
rylic Fabrics,” Journal of Materials Science: Materials in Medicine, Vol. 21, 2010, pp. 507-514. doi:10.1007/s10856-009-3900-4

[51] A. E. Toneli, "Improving Textiles with Cyclodextrins," 4th Inter, Conference Textile Research, Division National Research Centre, Cairo, 2007, pp. 64-72.

[52] Y. El Ghoul, N. Blanchemain, T. Laurent, C. Campagne, A. El Achari, S. Roudesli, M. Morcellet, B. Martel and H. F. Hildebrand, "Chemical, Biological and Microbiological Evaluation of Cyclodextrin Finished Polyamide Inguinal Meshes," Acta Biomaterialia, Vol. 4, 2008, pp. 1392-1400. doi:10.1016/j.actbio.2008.02.019

[53] A. Bendak, O. G. Allam and L. K. El-Gabry, "Treatment of Polyamides Fabrics with Cyclodextrins to Improve Some Properties,” Open Textile Journal, 2010.

[54] W. D. Schindler and P. J Hauser, "Chemical Finishing of Textiles,” Cambridge, Wood Head Publishing Ltd., Vol. 165, 2004. doi:10.1533/9781845690373

[55] B. Marcandalli, "Application of Plasma Technology on Textiles,” 3rd International Conference, Textile Research. Division, National Research Centre, Cairo, 2006, pp. 635-638.

[56] N. Abidi and E. Hequet, "Cotton Fabric Copolymerization Using Microwave Plasma, Universal Attenuated Total Reflectance-FITR Study,” Journal of applied polymer science, Vol. 93, 2004, pp. 145-154. doi:10.1002/app.20442

[57] T. Wakida, S. Cho, S. Choi, S. Tokino and M. Lee, "Effect of Low Temperature Plasma Treatment on Color of Wool and Nylon 6 Fabrics Dyed with Natural Dyes," Textile Research Journal, Vol. 68, 1998, pp. 848-853. doi:10.1177/004051759806801110

[58] C. Yu-Bin, T. Pei-Chiu, W. Mien-Win, H. Tien-Hsiang and H. Shan-hui, "A Study on Chitosan Modification of Polyester Fabrics, Fibers and Polymers,” Vol. 9, No. 3, 2008, pp. 1229-9197.

[59] J. M. Susie, P. Jonathan, W. Caldell, J. H. Anita, C. Katie, M. D. Jolon and G. B. warren, "Covalent Modification of the Wool Fiber Surface: The Attachment and Durability of Model Surface Treatment,” Textile Research Journal, Vol. 78, 2008, pp. 1087-1097. doi:10.1177/0040517507087852

[60] I. Holme, "Enzymes for Innovative Textile Treatments," Textile Magazine, No. 3, 2004, p. 8.

[61] A. P. Cavaco and G. M. Gübitz, "Textile Processing with Enzymes,” Cambridge, Woodhead Publishing, 2003. doi:10.1533/9781855738669

[62] G. F. Colbrie, S. Heumann and G. M. Gübitz, "Biotechnology in the Textile Industry: Enzymatic Modification of Synthetic Fibers," 2nd International Conference of Textile Research Division, NRC, Cairo, Egypt, 11-13 April, 2005, pp. 33.

[63] H. Uyama and Kobayashi, "Enzyme - Catalyzed Polymerization of Functional Polymers,” Journal of Molecular Catalysis Enzyme, Vol. 19, 2002, pp. 117-127. doi:10.1016/S1381-1177(02)00158-3
[64] I. Holme, "Innovative Technologies for High Performance Textiles," 3rd International Conference of Textile Research Division, NRC, Cairo, Egypt, April 2-4, 2006, pp. 466-482.

[65] S. József “Cyclodextrins in the Textile Industry,” Starch/Stärke, Vol. 55, 2003, pp. 191-196. doi:10.1002/star.200390050

[66] U. Denter, H.-J. Buschmann, D. Knittel and E. Schollmeyer, "Technology for Permanent Fixing of Cyclodextrin Derivatives Onto Textile Fibers,” Textilveredlung, Vol. 32, 1997, pp. 33-39.

[67] J. Zhao, D. Shanyi and T. Guishan, "Surface Modification of Acrylic Fiber by Grafting of Casein,” Journal of Macromolecular Science, Part A: Pure and Applied Chemistry, Vol. 44, No. 3, 2007, pp. 299-304. doi:10.1080/10601320601077351

[68] B. Marcandalli, “Application of Plasma Technology on Textiles," 3rd International Conference on Textile Processing: State of the Art and Future Developments of Textile Research Division, National Research Centre, Cairo, Egypt, 2006, pp. 635-638.

[69] T. Wakida, S. Tokino, S. Niu, H. Kawamura, Y. Sato, M. Lee, H. Uchiyama and H. Inagaki, "Surface Characteristics of Wool and Poly Ethylene Terephthalate) Fabrics and Fiber Treated with Low-Temperature Plasma under Atmospheric Pressure," Textile Research Journal, Vol. 63, 1993, pp. 433-438. doi:10.1177/004051759306300801

[70] T. Oktem, N. Seventekin, H. Ayhan and E. Piskin, "Modification of PAN Fabrics by in Situ-Plasma Polymerisation Method,” Melliand Textilber, Vol. 82, No. 3, 2001, pp. E51-E53.

[71] J. Kang and M. Sarmadi, "Plasma Treatment of Textilesynthetic Polymer-Based Textile," American Association of Textile Chemists and ColoristsReview, Vol. 4, No. 11, 2004, pp. 29-33.

[72] Y. Joanne, C. Kwong, M. S. Kwan and L. S. Kai, “Comprehensive Study of Polymer Fiber Surface Modifications Parts: Low Temperature Oxygen Plasma Treatment,” Polymer International, Vol. 53, 2004, pp. 634-639. doi:10.1002/pi.1278

[73] P. Malcik and J. petrovsky, "Contribution to the Plasma Chemical Treatment of Textile,” Textile, Vol. 38, No. 8, 1983, pp. 282-287.

[74] T. Oktem, N. Seventekin, H. Ayhan and E. Piskin, "Modification of PAN Fabrics by in Situ-Plasma Polymerisation Method,” Melliand Textilber, Vol. 82, No. 3, 2001, pp. E51-E53.

[75] Y. Joanne, C. Kwong, M. S. Kwan and L. S. Kai, "Low Temperature Plasma-Treated Nylon Fabrics," Journal of Materials processing technology, Vol. 23, No. 1, 2002, pp. 5-12.

[76] H. Watanabe and B. Tomoko, "Fluro Resin-Containing Modified Polyester Fibers with Improve Surface Smoothness,” Japan KokaiTokkyo Koho JP 06, Vol. 136, No. 616, 1994. 
[77] G. Deepti, S. periyasamy and B. Abhishek, "Basic Dye Able Polyester: A New Approach Using a VUV Excimer Lamp," Coloration Technology, Vol. 123, 2007, pp. 248-251.

[78] L. Kravets, S. Dmitriev, A. Gilman, A. Drachev and G. Dinescu, "Water Permeability of Poly (Ethylene Terphethalate) Track Membranes Modified by DC Discharge Plasma Polymerization of Dimethylaniline," Journal of Membrane Science, Vol. 263, 2005, p. 127. doi:10.1016/j.memsci.2005.04.012

[79] K. Dierk and E. Schollmeyer, "Surface Structuring of Synthetic Polymers by UV-Laser Irradiation Part IV. Applications of Excimer Laser Induced Surface Modification of Textile Materials Polymer,” International, Vol. 45, 1998, pp. 110-117.

[80] M. A. White, “The Effect of Chemical and Polymer Finishing Treatments on the Flammability of Fabrics for Protective Clothing," Fire safety Journal, Vol. 4, 1981, pp. 103-108. doi:10.1016/0379-7112(81)90009-6

[81] X. flambard, S. Bourbigot, R. Kozlowski, M. Muzyczek, B. Mieleniak, M. Ferreira, B. Vermeulen and F. Poutch, "Progress in Safety, Flame Retardant Textiles and Flexible Fire Barriers for Seats in Transportation," Polymer Degradation and Stability, Vol. 88, 2005, pp. 98-105. doi:10.1016/j.polymdegradstab.2004.02.024

[82] L. Danian, Q. Wen, L. Shiyan and Z. Zeqing, "Structure and Flame Retardation Mechanism of Hydrazine and Copper Ion-Modified Modacrylic Fibres," Zhongguo Fangzhi Daxue Xuebao, Vol. 15, No. 2, 1989, pp. 7-13.

[83] T. Jin-Shy, "The Effect of Flame-Retardants on the Properties of Acrylic and Modacrylic Fibres," Journal of Materials Science, Vol. 28, No. 5, 1993, pp. 1161-1167. doi:10.1007/BF01191947

[84] S. E. Fryer, "New Developments in Acrylic Carpet Fibres for Specific End-Uses," Journal of the Society of Dyers and Colourists, Vol. 90, No. 7, 1998, pp. 229-231. doi:10.1111/j.1478-4408.1974.tb03201.x

[85] H. C. V. Baeyer, “The Lotus Effect," Sciences, Vol. 40, 2000, pp. 12-15.

[86] J. H. Xin and W. A. Daoud, "Small-Scale Technology with the Promise of Big Rewards," Technical Textiles International, Vol. 3, 2003, pp. 13-15.

[87] N. A. G. Johnson, E. J. Wood, P. E. Ingham, S. J. McNeil and I. D. McFarlane, "Wool as a Technical Fibre," Journal of the Textile Institute, Vol. 94, 2003, pp. 26-41. doi:10.1080/00405000308630626

[88] B. T. Zhang, B. L. Liu, X. B. Deng, S. S. Cao, X. H. Hou and H. L. Chen, "Fabricating Super Hydrophobic Surfaces by Molecular Accumulation of Polysiloxane on Wool Textile Finishing," Colloid Polymer Science, Vol. 286, 2008, pp. 453-457. doi:10.1007/s00396-007-1801-y

[89] G. Freddie, T. Arai, G. M. Colonna, A. Boschi and M. Tsukada, "Binding of Metal Cations to Chemically Modified Wool and Antimicrobial Properties of the Wool-Metal Complexes," Journal of Applied Polymer
Science, Vol. 82, 2001, pp. 3513-3519.

[90] http:/ www. Azonano. Com / "Nano horizons announces smart silver anti-odor nanotechnology for wool," June 2007.

[91] Xu. Bingshe, M. Niu, L. Wei, W. Hou and X. Liu, "The Structural Analysis of Biomacromolecule Wool Fiber with Ag-Loading SiO2 Nano-Antibacterial Agent by U Radiation," Journal of photochemistry and photobiology A: Chemistry,Vol. 188, 2007, pp. 98-105. doi:10.1016/j.jphotochem.2006.11.025

[92] S. Kathirvelu, D. S. Louis and D. Bharathi, "Nanotechnology Applications in Textiles," Indian Journal of Science and Technology, Vol. 5, 2008, p. 1.

[93] G. David and P. P. Anthony, "Absorption of Nanoparticles by Wool,” Coloration Technology, Vol. 125, 2009, pp. 11-116.

[94] G. Sonar, A. Luís, A. Teresa, C. Noémia, P. S. António and F. M. Esteves, "Polymer Nanocomposites for Multifunctional Finishing of Textiles-A Review," Textile Research Journal, On line First, published on March 9, 2010

[95] J.Yeon, S. M. Kyun and I. K. Jui, "Electrospun TiO2 Electrodes for Dye-Sensitized Solar Cells," Journal of Nanotechnology, Vol. 15, 2004, pp. 1861-1865. doi:10.1088/0957-4484/15/12/030

[96] I. Vesva, Š. Zoran, V. Vesna, M. Darka, J. Petar, N. Jovan and R. Maja, "A Study of the Antibacterial Efficiency and Coloration of Dyed Polyamide and Polyester Fabrics Modified with Colloidal Ag Nanoparticles," Journal of the Serbian Chemical Society, Vol. 74, No. 3, 2009, pp. 349-357. doi:10.2298/JSC0903349I

[97] Z. Ping, S. Shu-ying, W. Bing, Z. Jian-bo and D. Chaohong, "Development of Nano-Antimicrobial dry Acrylic Fibres and Raschel Blankets,” Maofang Keji, Vol. 4, 2006, pp. 38-40.

[98] K. Hiroki and N. Hideo, "Photocatalytic Active Antibacterial Acrylonitrile Polymer Fibres Manufactured by Heat-Treating Acrylonitrile Polymer Fibres Containing Anti-Bacterial Metal Compounds at pH 1-6,” Kokai Tokkyo Koho JP., 0899682001.

[99] N. Hideo and N. Tetsuo, "Trichlorophyton-Inhibiting Silver-Containing Acrylonitrile Fibre Structures,” Kokai Tokkyo Koho JP., Vol. 45, 2005.

[100] H. J. Lee and S. H. Jeong, "Bacteriostasis of Nanosized Colloidal Silver on Polyester Nonwovens,” Textile Research Journal, Vol. 74, 2004, p. 442. doi:10.1177/004051750407400511

[101] S. Y. Yeo, H. J. Lee and S. H. Jeong, "Preparation of Nanocomposite Fibers for Permanent Antibacterial Effect,” Journal of Martial Science, Vol. 38, 2003, p. 2143, doi:10.1023/A:1023767828656

[102] http:/ www.nano-care.com/ "Nano-Coating for Glass Permanent Easy-to-Clean Coating Anti-Lime, Hygienic Effect,” January 2007. 